\title{
Links Between Genetic Groups, Host Specificity, and Ergot-Alkaloid Profiles within Claviceps purpurea (Fr.) Tul. on Slovenian Grasses
}

Matevž Likar, Department of Biology, Biotechnical Faculty, University of Ljubljana; Marjana Grandič ${ }^{\dagger}$ and Breda Jakovac Strajn, Institute of Food Safety, Feed and Environment, Department of Environment, Animal Nutrition, Welfare and Hygiene, Veterinary Faculty, University of Ljubljana; and Katarina Kos and Franci Aco Celar, Department of Agronomy, Biotechnical Faculty, University of Ljubljana, 1000 Ljubljana, Slovenia

\begin{abstract}
In the present study, the genetic relationships and ergot-alkaloid production of the fungus Claviceps purpurea on grasses were investigated, to determine any associations between grass host specificity, ergotalkaloid production, and geographic origin. C. purpurea sclerotia were obtained from wild and cultivated grasses along a 300-km climatic gradient, from sub-Mediterranean to continental climates. Twenty-one infected grass samples provided 39 sclerotia for analysis of the ergot alkaloids ergometrine, ergosine, ergotamine, ergocornine, ergocryptine, and ergocristine, and their "-inine" epimers, using liquid chromatography-tandem mass spectrometry. C. purpurea ribosomal DNA underwent molecular classification to determine any grass host or geographic specificity of ergot-alkaloid composition for the different operational taxonomic units.

Molecular analysis of sclerotia ribosomal DNA showed three genetic groups, with some associations with specific grass host taxonomic groups. The ergot-alkaloid composition data were in agreement with the data obtained by molecular methods. The most frequent ergot-alkaloid epimers were ergocristine, and ergosine. The total ergot-alkaloid concentrations in sclerotia varied from 59 to $4,200 \mathrm{mg} \mathrm{kg}^{-1}$, which corresponds to 0.059 to $4.2 \mathrm{mg} \mathrm{kg}^{-1}$ in animal feed (assuming ergot alkaloids at $1,000 \mathrm{mg} \mathrm{kg}^{-1}$ sclerotia). Therefore, grasses can be associated with significant levels of ergot alkaloids. In addition, the ergot-alkaloid compositions of C. purpurea sclerotia can be different for infections with different C. purpurea genetic groups, because these show different ergot-alkaloid compositions.
\end{abstract}

Ergot is a rare plant disease that can cause health problems in both humans and animals. The causal fungus is the ascomycete Claviceps purpurea (Fr.) Tul., which has a very broad host range, because it can parasitize $>400$ species in the Poaceae family, including wild and cultivated grasses in temperate regions. Cereal crop species vary in susceptibility to $C$. purpurea, with the decreasing order of susceptibility of rye, triticale, wheat, barley, and oat (Pažoutová 2002; Wegulo and Carlson 2011). Ergot results in only small yield losses in cereals, with a maximum of about $10 \%$ loss (Wegulo and Carlson 2011). However, $C$. purpurea contamination of cereals is more problematic because of the toxic ergot alkaloids that are produced in the sclerotia, which can represent 0.15 to $0.50 \%$ of the total sclerotium weight (Battilani et al. 2009; Krska and Crews 2008; Schardl et al. 2006). $C$. purpurea produces three major groups of ergot alkaloids: the clavine alkaloids, D-lysergic acid and its derivatives, and the ergopeptides (Hulvová et al. 2013). These toxins can cause convulsive or gangrenous ergotism, abortion, and death in humans and animals (Pertz and Eich 1999; Schiff 2006). Although today ergotism has been practically eliminated as a human disease, it is still a significant veterinary problem, particularly in cattle, horses, sheep, pigs, and chickens (Bennett and Klich 2003; Craig et al. 2015).

Cereal crops are at risk from several sources of primary inocula of $C$. purpurea from both within cropped areas (e.g., ascospores originating from microsclerotia carried over from the previous season or sclerotia imported with the seed) and external sources (e.g., field margins or noncultivated land set aside). Cereal crops are also at risk from secondary inocula (e.g., conidia from infected grasses

${ }^{\dagger}$ Corresponding author: M. Grandič; E-mail: marjana.grandic@vf.uni-lj.si

Funding: This study was supported by the Slovenian Research Agency and the Ministry of Agriculture, Forestry and Food through Research Project V4-1403.

*The $\boldsymbol{e}$-Xtra logo stands for "electronic extra" and indicates that one supplementary figure and one supplementary table are published online.

Accepted for publication 9 January 2018.

C) 2018 The American Phytopathological Society in the crop or margins or infected cereal plants). The importance of primary inocula compared with the risks from inocula generated from external sources is unclear. An understanding of the movement of inocula from field margins to crops is vital to determine whether grass margins act as a major source of $C$. purpurea inocula for cereals. Because sclerotia can survive in a field for only 1 year, and farmers generally practice crop rotation with noncereal crops, wild and cultivated grasses are crucial for the preservation of the pathogen near arable areas and for its spread into crop fields (Bayles et al. 2009; Mantle, 1988). Open-flowering and cross-pollinated cereals and grasses are more readily infected by $C$. purpurea, with wet and cool weather during the flowering period further promoting infection.

Because the composition of individual grass species in pastures and open meadows around crop fields can be highly variable, it is important to examine the possible host preferences of $C$. purpurea, along with the variability in the compositions of the ergot alkaloids in the sclerotia. This might improve predictions of the potential for infection of cereals and the resulting danger to cattle through ingestion of feed containing C. purpurea sclerotia (Mantle 1988). A study of the genetic variability, ergot-alkaloid composition, and conidial morphology of 100 isolates of $C$. purpurea revealed three habitatspecific $C$. purpurea groups: $\mathrm{G} 1$, from fields and open meadows, which includes all isolates from cereals; G2, from shady or wet habitats; and G3, from the salt marsh grass Spartina anglica (Pažoutová et al. 2000). The host preferences of these groups are not absolute, although they show habitat-connected specialization and some differences in their ergot-alkaloid profiles. This is in line with other reports that different $C$. purpurea isolates can produce various types of ergot alkaloids (Esser and Tudzynski 1978; Pažoutová 2002). In a subsequent study, Pažoutová et al. (2002) confirmed that the C. purpurea host plant does not influence the type of ergot alkaloids produced but can affect their ratio. Thus, ergot-alkaloid profiling can offer a practical method of characterizing local $C$. purpurea populations.

The overall aim of the present study was to compare the genetic relationships and alkaloid production across different $C$. purpurea populations on different grasses, in order to establish possible associations between plant-host specificity, ergot-alkaloid production, and geographic origin. We hypothesized that samples from different 
grass hosts would show a level of specificity that would be linked to their ergot-alkaloid profiles.

\section{Materials and Methods}

General description. Wild and cultivated grasses were screened for the presence of $C$. purpurea sclerotia along a $300-\mathrm{km}-l o n g$ climatic gradient that reached from a sub-Mediterranean to a continental climate. Infected grasses were collected and the sclerotia were analyzed for their ergot-alkaloid compositions, in terms of ergometrine, ergosine, ergotamine, ergocornine, ergocryptine, ergocristine, and their "-inine" epimers. The sclerotia were also used to molecularly classify the $C$. purpurea using their internal transcribed spacer (ITS) ribosomal (r)DNA regions, to

X94171 Fusarium proliferatum

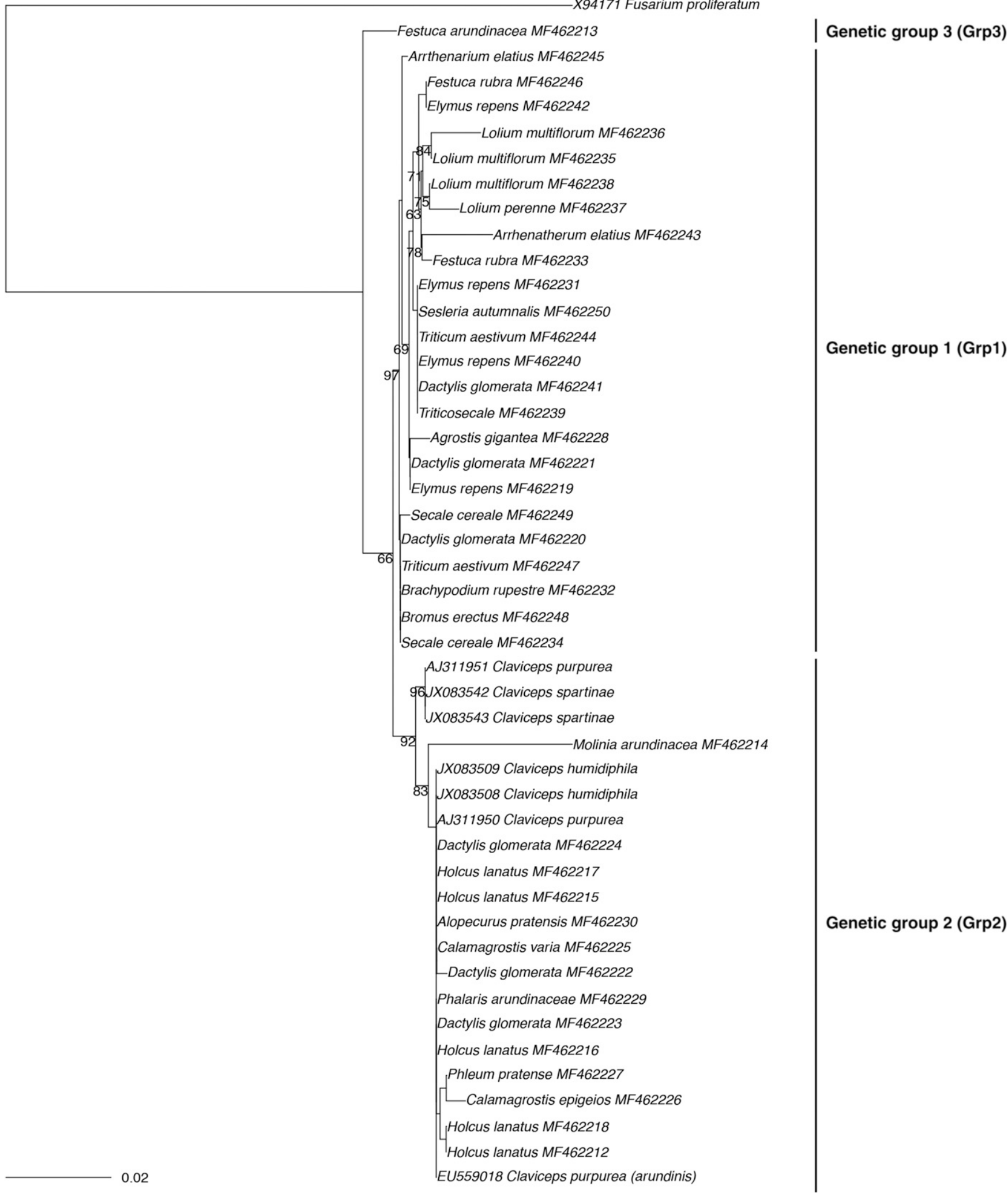

Fig. 1. Molecular phylogenetic analysis using the maximum-likelihood method. The evolutionary history was inferred using the Jukes-Cantor model with $\gamma$ distribution. The tree with the highest log likelihood is shown $(-1,470.646)$. The percentage of replicate trees in which the associated taxa clustered together in the bootstrap test are shown next to the branches (500 replicates; values $<60 \%$ are not shown). 
establish any differences in $C$. purpurea samples relating to the ergotalkaloids compositions and also in relation to the $C$. purpurea host or geographic specificities.

Sampling and preparation of sclerotia for analysis. In 2014, 39 samples were obtained from 21 grass species infected with $C$. purpurea that were collected at 22 locations in Slovenia (across eight geographic regions). The sclerotia were separated from the grass hosts, cleaned of debris, dissected out, and stored at $-20^{\circ} \mathrm{C}$.

Ergot-alkaloid analysis. Standards and chemicals. The ergotalkaloid standards of ergometrine, ergosine, ergotamine, ergocornine, ergocryptine, and ergocristine, and their -inine epimers, and MycoSep 150 Ergot columns were from Romer (Tulln, Austria). Stock standard solutions and mixed working standard solutions were prepared in acetonitrile and stored in amber glass vials at $-20^{\circ} \mathrm{C}$. The certified purity of individual standard substances was between $95.1 \pm 4.9$ and $99.0 \pm$ $1.0 \%$. The concentrations of individual ergot alkaloid stock standard solutions obtained by reconstituting the content of ampoules in $5 \mathrm{ml}$ of acetonitrile were specified by the producer as 100.1 to 101.7 and 25.1 to $25.7 \mu \mathrm{g} \mathrm{ml}^{-1}$ for individual -ine and -inine, respectively. In the mixed working standard solutions, the concentration of individual ergot alkaloid was set to $0.2 \mu \mathrm{g} \mathrm{ml}^{-1}$.

Acetonitrile, methanol (Sigma-Aldrich, Steinheim, Germany), acetic acid, and ammonium acetate (Merck, Darmstadt, Germany) were of proanalysis or liquid chromatography-mass spectrometry (LC-MS)grade purity. Deionized water was prepared using a Milli-Q system (Millipore, Bedford, MA). The extraction solution was acetonitrile and ammonium carbonate (in deionized water) at $0.2 \mathrm{~g} \mathrm{liter}^{-1}$ (84:16 [vol/vol]). For the final sample solution, these two components were mixed at 50:50 (vol/vol). The mobile phase for the LC-tandem MS (LC-MS/MS) consisted of component A as ammonium carbonate (in deionized water) at $0.2 \mathrm{~g} \mathrm{liter}^{-1}$ and component $\mathrm{B}$ as acetonitrile with 98 to $100 \%$ formic acid at $1 \mathrm{ml} \mathrm{liter}^{-1}$.

Analytical procedure. For the simultaneous determination of the ergot alkaloids, the procedure consisted of the extraction of these toxins from ground sclerotia samples using the acetonitrile and ammonium carbonate solution at $0.2 \mathrm{~g} \mathrm{liter}^{-1}$ (50:50) and LC-MS/MS. Sample preparation and toxin determination were based on analytical procedures described previously (Crews et al. 2009; Diana Di

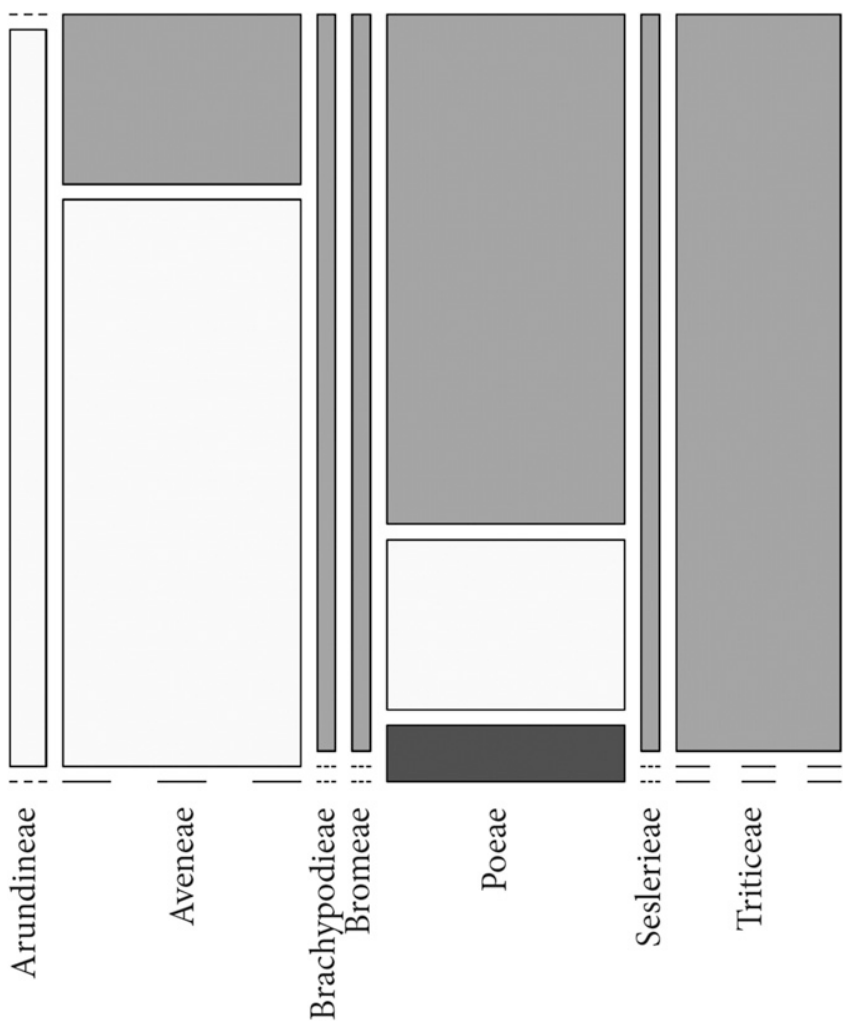

Fig. 2. Mosaic plot of hosts' affinity (tribe level) across the genetic groups.
Mavungu et al. 2012; Kokkonen and Jestoi 2010; Krska et al. 2008; Mulder et al. 2012). Ground sclerotia $(100 \mathrm{ml})$ were shaken in $50 \mathrm{ml}$ of extraction solution for $0.5 \mathrm{~h}$ using a digital linear shaker (IKA HS 501; IKA Labortechnik, Staufen, Germany). The extract (4.0 ml) was passed through a clean-up column (MycoSep; Romer, Tulln, Austria) and $1 \mathrm{ml}$ of the cleaned-up extract was evaporated under vacuum to dryness at $40^{\circ} \mathrm{C}$ using a vacuum evaporator (Syncore Polyvap; Büchi, Flawil, Switzerland). The dry residue was dissolved in $0.5 \mathrm{ml}$ of acetonitrile and ammonium carbonate at $0.2 \mathrm{~g} \mathrm{liter}^{-1}$ (50:50). An aliquot $(10 \mu \mathrm{l})$ of the solution was injected into the LC system (Acquity UPLC H Class) that was coupled to a triple-quadrupole MS (Xevo TQ MS) equipped with an electrospray ionization interface and the MassLynx software for data collection and processing (Waters, Milford, MA).

Chromatographic separation was performed on a phenyl-hexyl column (Ascentis Express; $2.7 \mu \mathrm{m}, 10$ by $2.1 \mathrm{~cm}$; Supelco, Bellefonte, PA). The two components of the mobile phase were mixed according to the gradient of $0 \mathrm{~min}, 95 \% \mathrm{~A} ; 1 \mathrm{~min}, 75 \% \mathrm{~A} ; 8 \mathrm{~min}, 40 \% \mathrm{~A}$; and 8.1

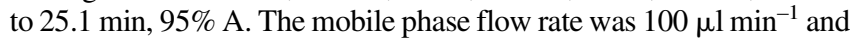
the column temperature was $30^{\circ} \mathrm{C}$. The MS/MS analysis was carried out using positive electrospray ionization, and the triple-quadrupole MS was operated in multiple-reactions monitoring mode. The capillary voltage was $3.8 \mathrm{kV}$, the desolvation temperature was $500^{\circ} \mathrm{C}$, and the ion source temperature was $150^{\circ} \mathrm{C}$. For quantification, matrix-matched calibration in the range 1.0 to $1,000 \mathrm{mg} \mathrm{kg}^{-1}$ was used.

Method validation. Limit of quantification of single ergot alkaloids was assumed to be between 0.1 and $1 \mathrm{mg} \mathrm{kg}^{-1}$. However, it was not tested consistently during the validation study because no blank sclerotia sample suitable for spiking was available. For determination of precision, a sample of sclerotia containing ergot alkaloids in the concentration range from 7 to $62 \mathrm{mg} \mathrm{kg}^{-1}$ (ergometrine, $21 \mathrm{mg} \mathrm{kg}^{-1}$; ergosine, $23 \mathrm{mg} \mathrm{kg}^{-1}$; ergocornine, $27 \mathrm{mg} \mathrm{kg}^{-1}$; ergocryptine, $62 \mathrm{mg} \mathrm{kg}^{-1}$; ergotamine, $58 \mathrm{mg} \mathrm{kg}^{-1}$; and ergocristine, $7 \mathrm{mg} \mathrm{kg}^{-1}$ ) was analyzed in replicates. For the determination of recovery, a sample was spiked with the ergot alkaloids at the concentration level of $6 \mathrm{mg} \mathrm{kg}^{-1}$.

The relative standard deviations of results obtained with the replicate analysis were 8 to $23 \%$ for single ergot alkaloid pairs (the lowest with ergosine and the highest with ergocristine). The recoveries for individual ergot alkaloid pairs were 51 to $109 \%$ (the lowest with ergocristine and the highest with ergocryptine). The lowest concentration of ergot alkaloids determined in sclerotia later in the study was $0.36 \mathrm{mg} \mathrm{kg}^{-1}$. Lower concentrations were reported as not detected.

Polymerase chain reaction amplification and sequencing of fungal rDNA. The rDNA was extracted from 30-mg (dry weight) samples of $C$. purpurea sclerotia using GenElute Plant Genomic DNA miniprep kits (Sigma-Aldrich), following the manufacturer's instructions. For the identification of the genetic groups of the C. purpurea samples, the ITS region of the rDNA was amplified using the ITS1F and ITS4 primers (Gardes and Bruns 1993; White et al. 1990). The polymerase chain reaction (PCR) conditions were $94^{\circ} \mathrm{C}$ for $1 \mathrm{~min}$, followed by 35 cycles of denaturation at $94^{\circ} \mathrm{C}$ for $35 \mathrm{~s}$, annealing at $55^{\circ} \mathrm{C}$ for $35 \mathrm{~s}$, and elongation at $72^{\circ} \mathrm{C}$ for $30 \mathrm{~s}$. The elongation step was increased by $5 \mathrm{~s}$ every cycle. The final extension was at $72^{\circ} \mathrm{C}$ for $10 \mathrm{~min}$. The PCR mixture $(25 \mu \mathrm{l})$ contained $2.5 \mu \mathrm{l}$ of $10 \times$ PCR buffer, $2.5 \mathrm{mM} \mathrm{MgCl}_{2}, 200 \mu \mathrm{M}$ each nucleotide, $500 \mathrm{nM}$ each primer, $0.75 \mathrm{U}$ of DNA polymerase, and $12.5 \mu \mathrm{l}$ of 100 -fold diluted template. Cycle-sequencing reactions were performed with the ITS1F and ITS4 primers using BigDye terminator Ready Reaction Cycle Sequencing kits on a DNA analyzer (ABI 3730xl; Applied Biosystems, Foster City, CA), as provided by the Macrogen Company (Seoul, Korea).

The rDNA sequences obtained were subjected to GenBank searches using the default option of gapped-BLAST (Altschul et al. 1997), and aligned with the closest matches and additional representatives of the groups from GenBank. The robustness of the internal branches was assayed by bootstrap analysis (500 runs). The results of the BLAST analysis are presented in Supplementary Table 1 . The function modelTest was used to compare the different nucleotide models, and this provided the lowest Akaike Information 
Criterion value for the $\mathrm{HKY}+\mathrm{G}$ model and lowest Bayesian information criterion value for the $\mathrm{JC}+\mathrm{G}$ model. Comparisons between the models using likelihood ratio statistics showed no statistically significant differences and, therefore, the simpler JC+G model was chosen. A maximum-likelihood tree (Felsenstein 1981) was calculated using the Phangorn library (Schliep 2011), as implemented in the statistical framework of R, version 3.3.2.

Minimum spanning (haplotype) networks were constructed for the ITS rDNA dataset using PopArt (population analysis with reticulate trees) (Bandelt et al. 1999), with the default settings. All of the rDNA sequence data were included in these analyses.

Statistical methods. Because the -inine isomers of ergot alkaloids form naturally over time, the data for individual isomeric pairs (e.g., ergosine/ergosinine) were summed up prior to statistical analyses. The summed values are reported under the native isomer (e.g., ergosine).

The compositional dissimilarity of the ergot alkaloids between $C$. purpurea sclerotia samples was estimated with Euclidean distances and analyzed in a hierarchical experimental design (with region, host tribe affinity, and $C$. purpurea genetic group as the grouping factors) using permutational multivariate analysis of variance (perMANOVA) (Anderson 2001). Analyses of variance (ANOVA) were performed with the adonis function of the $\mathrm{R}$ Vegan package (Oksanen et al. 2012), using 999 permutations. The possibility of significant effects arising due to differences in multivariate dispersion rather than compositional changes was tested on the basis of multivariate dispersion measurements within and between groups (using the betadisper function of the Vegan package). Genetic group 3 (Grp3) was not included in the analyses of the ergot-alkaloid compositions because it was identified only once.

The Euclidean distance matrixes obtained from the ergot-alkaloid composition datasets were analyzed by nonmetric multidimensional scaling using the metaMDS function of the $\mathrm{R}$ Vegan package (Oksanen et al. 2012). Statistical analysis of the total ergot-alkaloid concentrations was carried out in $\mathrm{R}$ with the build-in functions for ANOVA and Holm-Sidak posthoc tests (comparisons between geographic regions and plant hosts) and $t$ tests (comparisons between Grp1 and -2) at $P<0.05$. Correlations between individual ergot alkaloids and total ergot alkaloids were performed with Pearson's correlation tests, with the build-in functions in R.

To calculate the unique and shared effects of geographic location, host affinity (tribus), and C. purpurea genetic group, as well as how much variation in ergot-alkaloid composition was explained by each set of these variables, variation partitioning analysis (partial redundancy analysis) was performed. Variation partitioning analysis using the varpart function and the significance of each testable fraction in variation partitioning analysis was obtained from the functions $r d a$ and anova.cca. The functions varpart, rda, and anova.cca are all part of the Vegan package (Oksanen et al. 2012).

\section{Results}

Spatial diversity of $\boldsymbol{C}$. purpurea. The sclerotia obtained from 21 grass species were used for molecular classification of these $C$. purpurea according to their ITS rDNA. This yielded 39 sequences that allowed their separation into three genetic groups (Fig. 1, Grp1 to -3). Grp1 and -2 were represented by 14 and 24 sequences, respectively, whereas only a single sequence was obtained for Grp3, which was isolated from the tall fescue grass, Festuca arundinacea.

The haplotype networks that were constructed for the ITS rDNA dataset to illustrate the distribution of these three genetic groups (Supplementary Fig. 1) were consistent with the phylogenetic analysis, because they showed no common haplotypes. Grp3 was separated from Grp2 according to a large number of mutations. In contrast, the distinction between Grp1 and Grp2 was less clear, because the number of mutations among the members of the individual groups here were comparative to the number of mutations between the groups. However, the genetic groups identified within the $C$. purpurea sensu lato sequences obtained indeed showed different host preferences, because the grass tribe Tritineae was infected only by Grp2 (Fig. 2). Grp2 was also the most common colonizer of grasses from tribe Poeae, whereas tribe Aveneae was dominated by the fungi from Grp1. Grp3 was only obtained from the red fescue grass, F. rubra, from tribe Poeae. Dominance of a single genetic group of $C$. purpurea was also seen for the grass tribes Arundineae (Grp2) and Brachypodieae, Bromeae, and Seslerieae (Grp1), although these were collected in fewer samples (Fig. 2).

Table 3. Results of the permutational multivariate analysis of variance (perMANOVA) analysis and multivariate dispersion tests for the ergotalkaloid compositions of the Claviceps purpurea sclerotia, using geographical region, grass host tribe (tribus) association, and $C$. purpurea genetic group as the sources of diversity

\begin{tabular}{|c|c|c|c|c|}
\hline \multirow[b]{2}{*}{ Factor } & \multicolumn{3}{|c|}{$\operatorname{perMANOVA}^{\mathrm{z}}$} & \multirow{2}{*}{$\frac{\text { Multivariate dispersion test }}{P}$} \\
\hline & $F$ & $R^{2}$ & $P$ & \\
\hline Regions & 1.286 & 0.32 & 0.284 & 0.548 \\
\hline Host & 5.855 & 0.51 & 0.001 & 0.461 \\
\hline Genetic group & 24.026 & 0.56 & 0.001 & 0.103 \\
\hline
\end{tabular}

${ }^{\mathrm{z}}$ Numbers in bold indicate statistical significance at $P<0.05$.

Table 1. Mean concentrations of the ergot alkaloids in the sclerotia of Claviceps purpurea according to the grass host taxonomic tribe ${ }^{\mathrm{z}}$

\begin{tabular}{lrccccccc}
\hline & & \multicolumn{5}{c}{ Ergot alkaloids $\left(\mathbf{m g ~ k g}^{-1}\right)$} \\
\cline { 2 - 8 } Tribe & $\boldsymbol{n}$ & Ergometrine & Ergosine & Ergocornine & Ergocryptine & Ergotamine & Ergocristine & Total \\
\hline Arundinoideae & 1 & 67.0 & $1,517 \mathrm{a}$ & $761 \mathrm{a}$ & 225 & 14.5 & $1,174 \mathrm{a}$ & $3,761 \mathrm{a}$ \\
Aveneae & 5 & $60.4 \pm 13.7$ & $1,375 \pm 139 \mathrm{a}$ & $200 \pm 12.9 \mathrm{~b}$ & $171 \pm 33.9$ & $45.7 \pm 3.91$ & $1,372 \pm 177 \mathrm{a}$ & $3,225 \pm 281 \mathrm{a}$ \\
Poeae & 12 & $251 \pm 52.1$ & $759 \pm 134 \mathrm{ab}$ & $254 \pm 33.9 \mathrm{~b}$ & $414 \pm 51.7$ & $181 \pm 59.2$ & $967 \pm 132 \mathrm{ab}$ & $2,830 \pm 237 \mathrm{a}$ \\
Seslerieae & 1 & 33.6 & $46.2 \mathrm{~b}$ & $4.74 \mathrm{~b}$ & 6.01 & 259 & $30.6 \mathrm{~b}$ & $380 \mathrm{~b}$ \\
Triticeae & 8 & $214 \pm 74.4$ & $300 \pm 78.6 \mathrm{~b}$ & $255 \pm 108 \mathrm{~b}$ & $298 \pm 96.0$ & $149 \pm 45.6$ & $497 \pm 129 \mathrm{ab}$ & $1,715 \pm 307 \mathrm{ab}$ \\
\hline
\end{tabular}

${ }^{\mathrm{z}}$ Data are means \pm standard error. Data followed by different letters within columns are significantly different (Holm-Sidak posthoc tests; $P \leq 0.05$ ).

Table 2. Mean concentrations of the ergot alkaloids in the sclerotia of Claviceps purpurea according to their genetic groups

\begin{tabular}{|c|c|c|c|c|c|c|c|c|}
\hline \multirow[b]{2}{*}{ Group } & \multirow[b]{2}{*}{$n$} & \multicolumn{7}{|c|}{ Ergot alkaloids (mg kg-1) } \\
\hline & & Ergometrine & Ergosine & Ergocornine & Ergocryptine & Ergotamine & Ergocristine & Total \\
\hline 1 & 13 & $194 \pm 41.7$ & $442 \pm 70.4$ & $204 \pm 41.3$ & $307 \pm 59.7$ & $166 \pm 28.7$ & $662 \pm 100$ & $1,979 \pm 271$ \\
\hline 2 & 8 & $62.7 \pm 11.0$ & $1522 \pm 66.1$ & $281 \pm 70.1$ & $179 \pm 27.1$ & $40.5 \pm 5.12$ & $1,523 \pm 108$ & $3,610 \pm 179$ \\
\hline$P(1 \text { vs. } 2)^{\mathrm{z}}$ & $\ldots$ & 0.009 & $<0.001$ & $\mathrm{~ns}$ & ns & $<0.001$ & $<0.001$ & $<0.001$ \\
\hline
\end{tabular}

$\mathrm{z}$ Values from $t$ tests; ns $=$ not significant. 
Ergot alkaloids in $C$. purpurea sclerotia. In the sclerotia collected from these grass samples from eight different geographic regions of Slovenia, all of the ergot alkaloids screened for were found (i.e., ergometrine, ergosine, ergotamine, ergocornine, ergocryptine, and ergocristine, along with their corresponding -inine epimers). The concentrations of the total ergot alkaloids in the sclerotia were from 59.75 to $4,200 \mathrm{mg} \mathrm{kg}^{-1}$. The mean concentration was $2,443 \mathrm{mg} \mathrm{kg}^{-1}$ and the median was $2,687 \mathrm{mg} \mathrm{kg}^{-1}$. Among these ergot alkaloids, only ergosine $(R=0.84, P<0.001)$ and ergocristine $(R=0.87, P<0.001)$ showed significant correlations with the total ergot-alkaloid concentrations.

Comparison of these ergot alkaloids based on the region of the grass sampling did not reveal any statistically significant differences. The concentrations of the ergot-alkaloid epimers according to the grass host tribe showed statistically significant differences in some
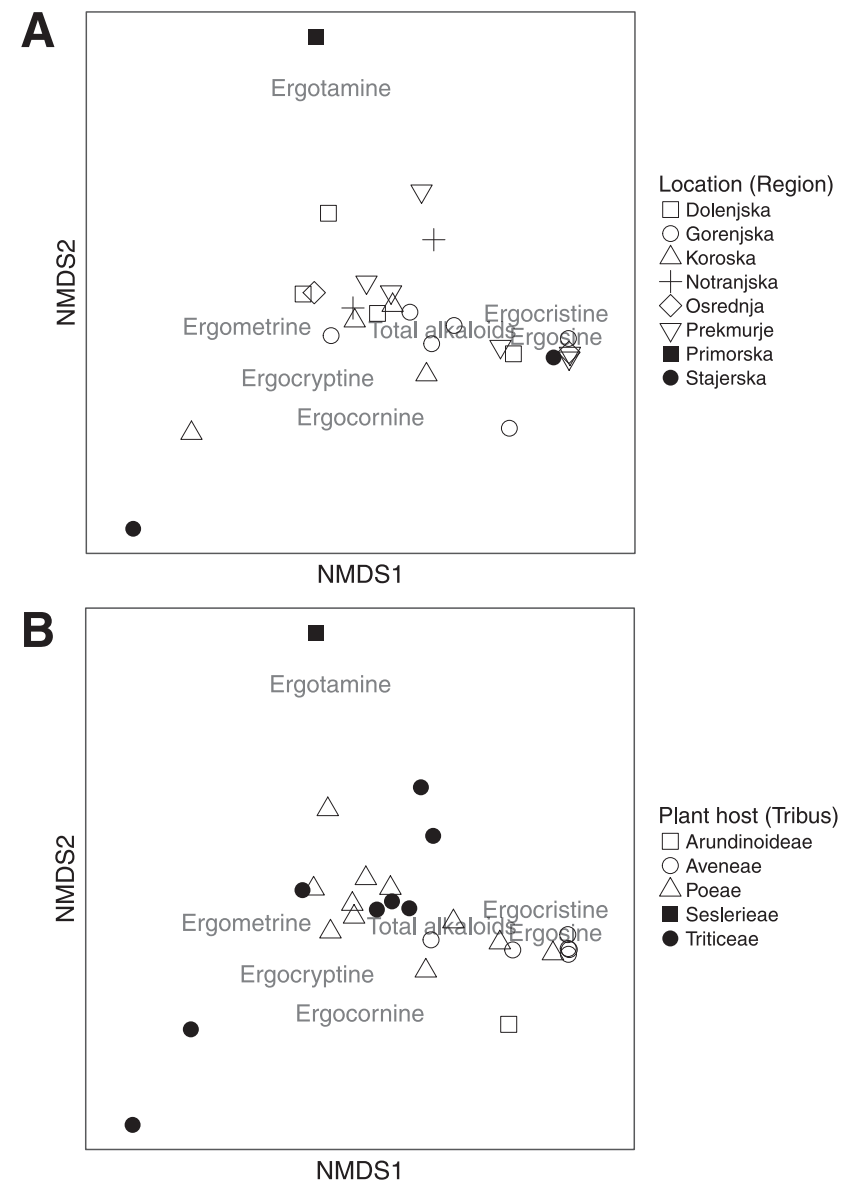

$\square$ Arundinoideae

$\bigcirc$ Aveneae

$\triangle$ Poeae

- Seslerieae

- Triticeae

NMDS1

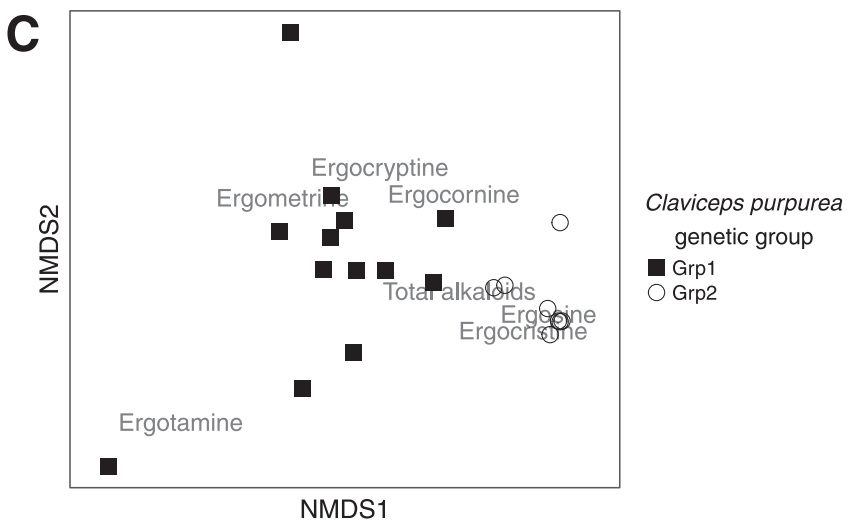

Fig. 3. Nonparametric multidimensional scaling analysis of ergot alkaloid profiles as biplots, with sample scores as points and ergot alkaloid loadings as text labels. Different shapes represent A, location of collection; B, plant hosts' tribe (tribus); and $\mathbf{C}$, Claviceps purpurea genetic group. cases: ergosine, ergocornine, ergocristine, and the total ergot alkaloids (Table 1). The lowest concentrations of the ergot alkaloids were measured in the sclerotia isolated from grass tribe Sesleriae, whereas the highest were measured in tribe Arundinoideae; however, both of these analyses were based on single grass tribe samples. Comparisons of the ergot alkaloids between the two more frequently identified genetic groups (i.e., Grp1 and Grp2) showed that the sclerotia classified as Grp2 had higher concentrations of total ergot alkaloids (Table 2) as well as higher concentrations of ergosine and ergocristine. The sclerotia of Grp1 had higher concentrations of ergometrine and ergotamine, whereas there were no statistically significant differences between these two genetic groups for the ergocornine and ergocryptine concentrations.

The perMANOVA analysis of the ergot-alkaloid compositions in these $C$. purpurea sclerotia collected from the different geographical regions indicated no statistically significant differences (Table 3 ). In contrast, there were statistically significant differences seen for the ergot-alkaloid compositions when the grass host tribe or genetic group was used as the grouping category (Grp3 was omitted because it was formed by a single sample).

The ordination plot of the ergot-alkaloid compositions of the sclerotia samples according to the geographical regions showed no clear separation between the different regions (Fig. 3A, stress value $=$ 0.031 ), which was in line with the results of the perMANOVA tests (Table 3). In contrast, grass host tribe affinity was an important factor for ergot-alkaloid composition (Fig. 3B, stress value $=0.031$ ). The ordination plot of the ergot-alkaloid compositions of the samples from the grass host tribes showed that the samples from tribe Aveneae were associated with ergosine and ergocristine, whereas the samples from tribe Seslerieae were associated with ergotamine. In addition, the $C$. purpurea genetic group was an important factor for ergot-alkaloid composition (Fig. 3C, stress value $=0.030$ ). The ordination plot of the ergot-alkaloid compositions of the samples showed that those from Grp2 were associated with ergosine and ergocristine.

With the geographic location as the explanatory variable for variations in the ergot-alkaloid compositions, there was no statistical significance seen for the data and, thus, these were not included in the variation partitioning analysis. The remaining explanatory variables, as grass host tribe associations and $C$. purpurea genetic groups, explained $63.9 \%$ of the total variation, with the grass host tribe associations explaining $10.4 \%$ of the total variation and the $C$. purpurea genetic group explaining $15.7 \%$ of the total variation. In addition, both explanatory variables jointly explained an additional $37.8 \%$ of the total variation in ergot-alkaloid composition.

\section{Discussion}

Molecular analysis of $C$. purpurea sclerotia collected from wild and cultivated grasses in eight different regions in Slovenia showed their rDNA separation into three genetic groups (Grp1 to -3), with some selection for specific grass host taxonomic groups seen. It appears that $C$. purpurea shows mild host preference, although this is not absolute (Pažoutová et al. 2000). However, this appears to be stronger for different development phases, because Pažoutová et al. (2002) observed that infection ability (formation of sphacelial stage and honeydew) was less host restricted than formation of mature sclerotia. Because host specificity at the species levels was not well pronounced here, we examined the taxonomic tribes inside these members of the family Poaceae. This showed that the grass tribe level was more informative, with a clearer picture of host preference of these different $C$. purpurea genetic groups obtained in the present study. This information can be used to improve the prediction of occurrence of specific C. purpurea groups (and their ergot alkaloids) in grasslands and fields.

The data for the concentrations of the individual and total ergot alkaloids in $C$. purpurea sclerotia isolated from wild and cultivated grasses from different regions in Slovenia obtained using LC-MS/MS are in agreement with data obtained by molecular methods. We have shown that the most frequent ergot-alkaloid epimers were ergocristine and ergosine. All of these ergot-alkaloid epimers were also highly 
correlated with the total ergot alkaloids. Our findings are consistent with data from other studies (Aboling et al. 2016; Uhlig and Petersen 2008; Uhlig et al. 2007). Uhlig at al. (2007) showed that ergocristine was the major alkaloid in most extracts from $C$. purpurea sclerotia harvested in Norway. The concentrations of alkaloids that were quantified from grass samples in Norway ranged from 0.2 to $9,300 \mathrm{mg} \mathrm{kg}^{-1}$, which is comparable with the data in the present study. Aboling et al. (2016) also showed ergocristine and ergosine as the most abundant ergot alkaloids associated with wild grasses. Ergocristine followed by ergosine were the major ergot alkaloids reported as associated with Holcus spp., as well as for Dactylis and Agrostis spp., which is consistent with the data from the present study. The maximum level of rye sclerotia in feed tolerated in the European Union is $1,000 \mathrm{mg} \mathrm{kg}^{-1}$ (European Union 2002). Considering the assumed average ergot-alkaloid content in sclerotia in central Europe $(0.2 \%)$, a guidance level (i.e., tolerance limit) of $2 \mathrm{mg} \mathrm{kg}^{-1}$ for total ergot alkaloids in feed was suggested by Bürk et al. (2006) and Münzing (2006). In the present study, we found total ergot-alkaloid concentrations of 59 to $4,200 \mathrm{mg} \mathrm{kg}^{-1}$ sclerotia, which correspond to 0.059 to $4.2 \mathrm{mg} \mathrm{kg}^{-1}$ in animal feed (assuming that the feed contains sclerotia at $1 \mathrm{~g} \mathrm{~kg}^{-1}$ of feed). Based on the estimations that the animal feed contained sclerotia at $1 \mathrm{~g} \mathrm{~kg}^{-1}$ if feed and that the sclerotia contained $0.2 \%$ ergot alkaloids, we can conclude that the data in the present study are comparable with the calculated levels of ergot alkaloids in animal feed given above.

Some differences in the ergot-alkaloid compositions were observed for the different genetic groups defined in the present study. Because these different genetic groups also showed some association with the individual grass host taxonomic tribes, this resulted in specific ergot alkaloids being more characteristic of certain grass groups. These findings are in line with the hypothesis from other studies that the production of specific ergot alkaloids is not influenced by the grass host species, whereas the grass host might affect the relative ratios of the various alkaloids (Negård et al. 2015; Pažoutová et al. 2000, 2002). However, it appears that differences in ergot-alkaloid compositions associated with different hosts is more a result of colonization by specific genetic groups of $C$. purpurea. The data from the variation partitioning analysis that showed high overlap between the effects of the grass host tribe association and the C. purpurea genetic group appear to support this.

From the data obtained in the present study and the data in the literature (Boestfleisch et al. 2015; Pažoutová et al. 2000; Uhlig and Petersen 2008), we can assume that grasses can be associated with significant levels of ergot alkaloids. Also, the ergot-alkaloid compositions can change as a result of infection with different $C$. purpurea genetic groups, which show differences in the production of the individual ergot alkaloids. More importantly, one of the genetic groups showed increased production of ergocristine, and this has been shown to have the highest toxicity in a comparative study that tested the toxicities of the major ergot alkaloids on human cells (Mulac and Humpf 2011). Therefore, in addition to ergot-alkaloid monitoring in cereals for human consumption and animal feed, better management of pastures and grasslands around crop fields is an important factor for prevention of ergotism. This is especially important as more and more agricultural land is transferred to sustainable farming techniques, because these involve changes in field margins in relation to their grass species composition and management.

\section{Acknowledgments}

We thank C. Berrie for English revision of the manuscript.

\section{Literature Cited}

Aboling, S., Drotleff, A. M., Cappai, M. G., and Kamphues, J. 2016. Contamination with ergot bodies (Claviceps purpurea sensu lato) of two horse pastures in northern Germany. Mycotoxin Res. 32:207-219.

Altschul, S. F., Madden, T. L., Schäffer, A. A., Zhang, J., Zhang, Z., Miller, W., and Lipman, D. J. 1997. Gapped BLAST and PSI-BLAST: A new generation of protein database search programs. Nucleic Acids Res. 25:3389-3402.

Anderson, M. J. 2001. A new method for non-parametric multivariate analysis of variance. Austral Ecol. 26:32-46.

Bandelt, H., Forster, P., and Röhl, A. 1999. Median-joining networks for inferring intraspecific phylogenies. Mol. Biol. Evol. 16:37-48.
Battilani, P., Costa, L. G., Dossena, A., Gullino, M. L., Marchelli, R., Galaverna, G., Pietri, A., Dall'Asta, C., Giorni, P., Spadaro, D., and Gualla, A. 2009. Scientific information on mycotoxins and natural plant toxicants. Scientific/ Technical report submitted to EFSA. Online publication. http://onlinelibrary. wiley.com/doi/10.2903/sp.efsa.2009.EN-24/pdf

Bayles, R., Gladders, P., Hollins, W., and Kenyon, D., and Thomas, J. 2009. Towards a sustainable whole-farm approach to the control of ergot. HGCA, Project Report No. 456

Bennett, J. W., and Klich, M. 2003. Mycotoxins. Clin. Microbiol. Rev. 16: 497-516.

Boestfleisch, C., Drotleff, A. M., Ternes, W., Nehring, S., Pažoutová, S., and Papenbrock, J. 2015. The invasive ergot Claviceps purpurea var. spartinae recently established in the European Wadden Sea on common cord grass is genetically homogenous and the sclerotia contain high amounts of ergot alkaloids. Eur. J. Plant Pathol. 141:445-461.

Bürk, G., Höbel, W., and Richt, A. 2006. Ergot alkaloids in cereal products. Results from the Bavarian Health and Food Safety Authority. Mol. Nutr. Food Res. 50:437-442.

Craig, A. M., Klotz, J. L., and Duringer, J. M. 2015. Cases of ergotism in livestock and associated ergot alkaloid concentrations in feed. Front Chem. 3:8.

Crews, C., Anderson, W. A. C., Rees, G., and Krska, R. 2009. Ergot alkaloids in some rye-based UK cereal products. Food Addit. Contam. Part B 2:79-85.

Diana Di Mavungu, J., Malysheva, S. V., Sanders, M., Larionova, D., Robbens, J., Dubruel, P., Van Peteghem, C., and De Saeger, S. 2012. Development and validation of a new LC-MS/MS method for the simultaneous determination of six major ergot alkaloids and their corresponding epimers. Application to some food and feed commodities. Food Chem. 135:292-303.

Esser, K., and Tudzynski, P. 1978. Genetics of the ergot fungus Claviceps. Purpurea. I. Proof of a monoecious life cycle and segregation patterns for mycelial morphology and alkaloid production. Theor. Appl. Genet. 53:145-149.

European Union. 2002. Directive 2002/32/EC of the European Parliament and of the Council of 7 May 2002 on undesirable substances in animal feed. OJ L 140, 30.5.2002, 10-21

Felsenstein, J. 1981. Evolutionary trees from gene frequencies and quantitative characters: Finding maximum likelihood estimates. Evolution 35:1229-1242.

Gardes, M., and Bruns, T. D. 1993. ITS primers with enhanced specificity of basidiomycetes: Application to the identification of mycorrhizae and rusts. Mol. Ecol. 2:113-118.

Hulvová, H., Galuszka, P., Frébortová, J., and Frébort, I. 2013. Parasitic fungus Claviceps. as a source for biotechnological production of ergot alkaloids Biotechnol. Adv. 31:79-89.

Kokkonen, M., and Jestoi, M. 2010. Determination of ergot alkaloids from grains with UPLC-MS/MS. J. Sep. Sci. 33:2322-2327.

Krska, R., and Crews, C. 2008. Significance, chemistry and determination of ergot alkaloids: A review. Food Addit. Contam. Part A. 25:722-731.

Krska, R., Stubbings, G., Macarthur, R., and Crews, C. 2008. Simultaneous determination of six major ergot alkaloids and their epimers in cereals and foodstuffs by LC-MS/MS. Anal. Bioanal. Chem. 391:563-576.

Mantle, P. 1988. Claviceps purpurea (Fr.) Tul. Pages 274-276 in: European Handbook of Plant Diseases. I. M. Smith, J. Dunez, R. A. Lelliott, D. H. Phillips, and S. A. Archer, eds. Blackwell Scientific Publications, Oxford.

Mulac, D., and Humpf, H.-U. 2011. Cytotoxicity and accumulation of ergot alkaloids in human primary cells. Toxicology 282:112-121.

Mulder, P. P. J., Van Raamsdonk, L. W. D., Van Egmond, H. J., Voogt, J., Van Brakel, M. W., Van der Horst, G. M., and De Jong, J. 2012. Dutch survey ergot alkaloids and sclerotia in animal feeds. Report 2012.005. RIKILT. Online publication. http://edepot.wur.n1/234699

Münzing, K. 2006. Technical possibilities of minimizing of ergot alkaloids in cereals J. Verbraucherschutz Lebensmittel. (J. Consum. Prot. Food Saf.) 1:155-159.

Negård, M., Uhlig, S., Kauserud, H., Andersen, T., Høiland, K., and Vrålstad, T. 2015. Links between genetic groups, indole alkaloid profiles and ecology within the grass-parasitic Claviceps purpurea species complex. Toxins (Basel) 7:1431-1456.

Oksanen, J., Blanchet, F. G., Kindt, R., Legendre, P., O’Hara, R. B., Simpson, G. L., Solymos, P., Stevens, M. H. H. and Wagner, H. 2012. Vegan: Community Ecology Package. R Package version. Online publication. https://cran.r-project. $\mathrm{org} / \mathrm{web} /$ packages/vegan/index.html

Pažoutová, S. 2002. The evolutionary strategy of Claviceps. Pages 329-354 in: Clavicipitalean Fungi: Evolutionary Biology, Chemistry, Biocontrol and Cultural Impacts. F. White, C. W. Bacon, and N. L. Hywel-Jones, eds. M. Dekker, New York.

Pažoutová, S., Cagaš, B., Kolínská, R., and Honzátko, A. 2002. Host specialization of different populations of ergot fungus (Claviceps purpurea). Czech J. Genet. Plant Breed. 38:75-81.

Pažoutová, S., Olsovska, J., Linka, M., Kolinska, R., and Flieger, M. 2000 Chemoraces and habitat specialization of Claviceps purpurea populations. Appl. Environ. Microbiol. 66:5419-5425.

Pertz, H., and Eich, E. 1999. Ergot alkaloids and their derivatives as ligands for serotoninergic, dopaminergic, and adrenergic receptors. Pages 411-440 in: Ergot: The Genus Claviceps. V. Křen and L. Cvak, eds. Harwood Academic Publishers, Amsterdam, The Netherlands.

Schardl, C. L., Panaccione, D. G., and Tudzynski, P. 2006. Ergot alkaloids-Biology and molecular biology. Alkaloids 63:45-86. 
Schiff, P. L. 2006. Ergot and its alkaloids. Am. J. Pharm. Educ. 70: Article 98. Schliep, K. P. 2011. Phangorn: Phylogenetic analysis in R. Bioinformatics 27: 592-593.

Uhlig, S., and Petersen, D. 2008. Lactam ergot alkaloids (ergopeptams) as predominant alkaloids in sclerotia of Claviceps purpurea from Norwegian wild grasses. Toxicon 52:175-185.

Uhlig, S., Vikøren, T., Ivanova, L., and Handeland, K. 2007. Ergot alkaloids in Norwegian wild grasses: A mass spectrometric approach. Rapid Commun. Mass Spectrom. 21:1651-1660.
Wegulo, S. N., and Carlson, M. P. 2011. Ergot of small grain cereals and grasses and its health effects on humans and livestock. Univ. Nebr. Ext. EC1880. Online publication. http://extensionpublications.unl.edu/assets/ pdf/ec1880.pdf

White, T. J., Bruns, T., Lee, S., and Taylor, J. W. 1990. Amplification and direct sequencing of fungal ribosomal RNA genes for phylogenetics. Pages 315-322 in: PCR Protocols: A Guide to Methods and Applications. M. A. Innis, D. H. Gelfand, J. J. Sninsky, and T. J. White, eds. Academic Press, Inc., London. 